\title{
Pengaruh Endorphin Massage Terhadap Intensitas Nyeri Pada Ibu Bersalin
}

\author{
Nurun Ayati khasanah, Wiwit Sulistyawati \\ STIKes Majapahit Mojokerto \\ Corresponding author: Nurun Ayati khasanah (nurun.ayati@gmail.com) \\ Received: December, 16 2019; Accepted: January, 19 2020; Published: March, 152020
}

\begin{abstract}
ABSTRAK
Proses persalinan identik dengan rasa nyeri yang akan dijalani. Wanita yang melakukan persalinan pervaginam selalu mengalami rasa sakit saat melahirkan, terutama saat fase aktif persalinan pervaginam tahap 1. Menghilangkan rasa nyeri merupakan hal yang penting salah satu merode adalah Endorphin Massage sebagai teknik sentuhan ringan mengelola rasa sakit dan relaksasi. Penelitian ini bertujuan untuk Menganalisis pengaruh endorphin massage terhadap intensitas rasa nyeri dan percepatan kala I. Desain penelitian ini menggunakan analitik dengan rancangan pre test - post test Design. Penelitian ini dilakukan pada 24 responden dengan metode purposive sampling yang dilakukan pada bulan April - juni 2019. Hasil uji statistik dengan menggunakan paired sample test untuk menganalisis pengaruh massage endhorpin terhadap intensitas nyeri persalianan didapatkan nilai signifikan $0.000(\mathrm{P}<0.05)$ yaitu terdapat pengaruh positif massage endhorpin terhadap penurunan intensitas nyeri pada ibu kala I. Petugas kesehatan perawat / bidan dapat menggunakan massage endhorpin untuk mengurangi nyeri dalam memberikan pelayanan sebagai salah satu metode mengurangi rasa nyeri persalinan.
\end{abstract}

Kata Kunci: Massage Endhorpin, Intensitas Nyeri, Persalinan

This is an open-acces article distributed under the terms of the Creative Commons Attribution-ShareAlike 4.0 International License.

\section{PENDAHULUAN}

Persalinan merupkan proses pengeluaran bayi yang ditandai dengan kontraksi pada rahim sehingga menimbulkan rasa nyeri selama bayi belum lahir. Wanita yang melakukan persalinan pervaginam selalu mengalami nyeri saat melahirkan, terutama saat fase aktif persalinan pervaginam kala 1. Nyeri persalinan merupakan proses fisiologi yang terjadi dimana dinding otot rahim secara alami berkontraksi untuk membuka servik sehingga kepala bayi terdorong kearah panggul. Kontraksi pada otot - otot rahim membuat otot uterus menjadi hipoksia dimana servik meregang Nyeri pada persalinan kala I disebabkan oleh munculnya kontraksi otot-otot uterus, hipoksia dari otot-otot yang mengalami kontraksi, peregangan serviks, kurangnya suplai darah pada korpus uteri, dan segmen bawah rahim yang meregang. Nyeri yang ditimbulkan melalui saraf sensorif torakal bawah, saraf spinalis T11-12, lumbal atas dan saraf simpatik, dimana semua saraf bejalan mulai dari perifer melalui medulla spinalis, batang otak, thalamus dan kortek serebri (Antik, 2017) 
Selama persalinan, wanita mengalami tingkat rasa sakit yang hebat, stres yang dapat berpengaruh tidak baik terhadap bayi. Obat penghilang rasa sakit telah banyak digunakan untuk wanita yang melahirkan bayi, tetapi saat ini, karena beberapa keterbatasan yang diketahui dan efek samping yang serius, metode non farmakologis seperti terapi pijat dan musik sedang direkomendasikan secara luas. Terapi pijat mempengaruhi kulit permukaan, jaringan lunak, otot, tendon, ligamen dan fascia dengan teknik sistematis. Menggunakan mekanisme pelepasan endorfin, mengendalikan gerbang saraf dan merangsang saraf simpatik, terapi pijat dapat menyebabkan relaksasi otot. Keuntungan dari terapi pijat untuk wanita yang melahirkan bayi baik secara fisik (manipulasi fisik jaringan tubuh lunak) atau secara psikologis (energi penyembuhan positif yang dipancarkan selama manipulasi) (Aprilia, 2010).

Terapi massage endhorpin, mengurangi konsentrasi rangsangan pasien, dapat mengurangi kecemasan dan sensasi sakit. Relaksasi adalah salah satu efek psikologis dari terapi massage yang dapat menurunkan denyut jantung, pernapasan, dan metabolisme. Massage diberikan pada ibu dalam posisi berbaring miring, dengan bantal diposisikan di belakang punggung dan di antara kedua kakinya untuk penyangga. tekanan sedang diberikan dalam urutan berikut selama 10 menit. Massage dimulai kepala dan leher kemudian menuju punggung, pinggang dan kaki. Wanita hamil yang akan bersalin mengalamin peningkatan rasa nyeri yang menyebabkan peningkatan kadar kortisol dan norepinefrin dan rendahnya tingkat dopamin dan serotonin, kemudian melahirkan bayi baru lahir dengan gejala seperti depresi, peningkatan kadar kortison dan norepinefrin (hormon stres) dan kadar dopamin dan serononin yang lebih rendah (Esti, 2012).

Massage memiliki efek positif pada wanita yang mengalami nyeri pada ibu bersalin dengan mengurangi hormon stres dan aktivitas janin yang rendah. Setelah terapi massage endhorpin ibu bersalin memiliki kecemasan yang lebih rendah, sakit kaki dan punggung dan komplikasi kebidanan yang lebih sedikit, sedangkan yang baru lahir dalam keadaan baik. terapi massage meningkatkan serotonin dan pada gilirannya menurunkan kortisol dan depresi. Selain itu, serotinin tercatat mengurangi nyeri kaki dan punggung. Terapi massage juga diharapkan untuk meningkatkan dopamin dan akhirnya mengurangi norepinefrin dan kecemasan. Massage dapat berfungsi sebagai intervensi yang efektif untuk ibu bersalin menurunkan intensitas nyerinya (Supliani,2017).

Menurut teori Nightingale, manusia kebutuhan bersifat holistik termasuk kebutuhan fisiologis, kebutuhan psikologis, sosial, dan spiritual sehat dan tidak sehat. Ini pendekatan holistik yang diterapkan antara lain terapi komplementer yang dikombinasikan dengan terapi medis konvensional. Satu jenis terapi komplementer yang telah dibuktikan oleh literatur dalam mengurangi intensitas nyeri melalui mekanisme fisiologis, psikologis, sosial, dan spiritual adalah massage endhorpin. Beberapa penelitian telah membuktikan manfaat massage kaki secara fisiologis dan psikologis Salah satu efek fisiologis dari pijat kaki adalah mengurangi tekanan darah. Studi Hayes dan Cox menunjukkan bahwa pijat kaki telah mengurangi tekanan darah, detak jantung, dan laju pernapasan. Selain itu, pijat kaki juga menurunkan Mean Arterial Pressure (MAP), denyut jantung, dan laju pernapasan serta peningkatan saturasi oksigen (Rahmawati,2013) .

Massage endhorpin merupakan sentuhan ringan untuk relaksasi dan pengurangan rasa sakit, oleh karena itu massage endhorpin ini bisa dilakukan pada ibu bersalin yang mengalami nyeri berat, sedang melalui sentuhan pendamping persalinan sehingga menimbulkan perasaan tenang dan rileks pada akhirnya denyut jantung dan tekanan darah menjadi normal. Penatalaksanaan nyeri pada ibu bersalin perlu mendapat perhatian dari penolong agar ibu 
bersalin terhindar dari trauma persalinan yang bisa menyebabkan terjadinya post partum blus pada ibu (mander, 2012). Sesuai dengan dengan program yang dicanangkan oleh Kementrian Kesehatan (Kemenkes) yaitu program Making Pregnancy Saver (MPS) dengan salah satu aspek penatalaksanaan dalam persalinan yaitu aspek sayang ibu. Salah satu tehnik non farmakologi adalah massage untuk nyeri. Beberapa penelitian sudah dilakukan untuk massage baik dirumah sakit ataupun klinik bersalin, Rumah Bersalin masih belum dilaksanakan, termasuk di PMB M. Dari data diatas pijat ibu hamil merupakan sentuhan terapeutik, hipnosis, akupunktur dan akupresur untuk mengurangi nyeri persalinan di PMB Mudlikah kec ngoro kab mojokerto tahun 2019.

\section{METODE}

Penelitian ini merupakan penelitian analitik yang dilakukan secara eksperimental dengan jenis penelitian pre test - post test Design dilakukan pada bulan Mei - Juli 2019 Penelitian ini menggunakan desain Eksperimental. Penelitian ini menggunakan data primer dan sekunder . Data primer bersumber dari observasi intensitas nyeri, untuk data sekunder bersumber dari data PMB (praktek mandiri Bidan). Populasi sebanyak 24 responden yaitu ibu bersalin kala I seluruh ibu bersalin di praktek mandiri bidan $\mathrm{M}$ di kecamatan ngoro mojokerto. Tehnik sampling pada penelitian ini adalah non probability sampling dengan purposive sampling. untuk hasil observasi intensitas nyeri dengan menggunakan paired sample test atau uji - $\mathrm{t}$ sampel berpasangan dengan kemagnaan $\rho<0,05$ maka $\mathrm{H}_{\mathrm{o}}$ (hipotesa nol) ditolak, artinya ada pengaruh Endorphin massage terhadap intensitas rasa nyeri dan percepatan kala I.

\section{HASIL PENELITIAN}

Tabel 1. Data skala nyeri sebelum dan sesudah perlakuan massage endorphin di PMB M dikecamatan ngoro Mojokerto, Mei - Juli 2019.

\begin{tabular}{lcccc}
\hline \multirow{2}{*}{ Intensitas nyeri } & \multicolumn{4}{c}{ Pengamatan } \\
\cline { 2 - 5 } & \multicolumn{2}{c}{ Sebelum } & Sesudah \\
\cline { 2 - 5 } & $\mathrm{f}$ & 0 & 0 & $\%$ \\
\hline Tidak nyeri & 0 & 0 & 2 & 8.34 \\
Nyeri ringan & 0 & 4.17 & 17 & 70.83 \\
Nyeri sedang & 1 & 20.83 & 5 & 20.83 \\
Nyeri berat & 5 & 75 & 0 & 0 \\
Nyeri sangat berat & 18 & 100 & 24 & 100 \\
\hline Jumlah & 24 & & & \\
\hline
\end{tabular}

Berdasarkan tabel 2 responden penelitian sebelum diberikan massage endhorpin yang mengalami nyeri sangat berat 18 orang (41.6\%), Sesudah diberi massage endhorpin mengalami nyeri sedang 17 orang ( $50 \%)$.

Tabel 2. Data skala nyeri bourbonais pada kelompok sebelum dan sesudah perlakuan massage endorphin di PMB M di kecamatan ngoro Mojokerto, Mei Juli 2019.

\begin{tabular}{c|c|c|c}
\hline Subyek & $\begin{array}{c}\text { Skor awal } \\
\text { Massa endorphin }\end{array}$ & $\begin{array}{c}\text { Skor akhir } \\
\text { Massa endorphin }\end{array}$ & Perubahan \\
\hline 1 & 9 & 7 & 2 \\
\hline
\end{tabular}




\begin{tabular}{|l|l|l|l}
\hline 2 & 7 & 2 & 5 \\
3 & 9 & 7 & 2 \\
4 & 9 & 7 & 2 \\
5 & 7 & 5 & 2 \\
6 & 9 & 7 & 2 \\
7 & 7 & 5 & 2 \\
8 & 7 & 5 & 2 \\
9 & 9 & 5 & 4 \\
10 & 9 & 5 & 4 \\
11 & 9 & 7 & 2 \\
12 & 9 & 2 & 2 \\
13 & 7 & 5 & 2 \\
14 & 7 & 5 & 2 \\
15 & 9 & 5 & 4 \\
16 & 9 & 5 & 4 \\
17 & 9 & 5 & 4 \\
18 & 5 & 5 & 4 \\
19 & 9 & 5 & 4 \\
20 & 9 & 5 & 4 \\
21 & 9 & 5 & 4 \\
22 & 10 & 5 & 5 \\
23 & 9 & 5 & 4 \\
24 & 9 & 5 & 4 \\
\hline Rerata & 8.375 & 5.16 & 3.16 \\
\hline Ber & & \\
\hline
\end{tabular}

Berdasarkan tabel 4 rerata skor awal pada kelompok yaitu 8.375 sebelum massage endorphin menunjukkan penurunan nyeri setelah diberikan massage rerata 5.16 sehingga rerata skor akhir 3.16

Berdasarkan uji analisis t-test dengan tingkat kemaknaan $(\mathrm{p}<0.05)$ didapatkan nilai $(\mathrm{P}=0,00)$ sesudah diberikan perlakuan hal ini menunjukkan bahwa massage endorphin memiliki efek penurunan intensitas nyeri yang bermakna pada ibu inpartu kala I fase aktif

\section{PEMBAHASAN}

Berdasarkan hasil penelitian didapati penurunan intensitas nyeri yang signifikan setelah diberi massage endhorpin. Hasil penelitian sebelum diberikan massage endhorphin mengalami nyeri sangat berat 18 orang $(75 \%)$, dan Sesudah diberiakan massage endhorpin mengalami perubahan mengalami nyeri sedang 17 orang $(70.83 \%)$. Pada penelitian ini massage endhorpin diberikan selama kontraksi. Massage endhorpin dapat menimbulkan pengaruh fisiologis terhadap tubuh. Pada penelitian ini didapatkan nilai $(\mathrm{P}=0,000)$ sesudah diberikan perlakuan hal ini menunjukkan bahwa massage endorphin memiliki efek menurunkan nyeri yang bermakna pada ibu inpartu kala I fase aktif. Pemberian massage endhorpin pada ibu bersalin merupakan tehnik relaksasi untuk menurunkan rasa sakit, endhorphin terdiri dari 30 unit asam amino seperti ketokolamin, kortikotrofin, kortisol yang diproduksi oleh tubuh berfungsi menghilangkan rasa sakit dan menurunkan stress. Proses relaksasi ini memperkuat ikatan suami dan istri dalam persiapan persalinan. Sentuhan yang dilakukan membantu meningkatkan pelepasan hormon oksitosin dan melalui peningkatan endhorpin transmisi sinyal antara sel saraf sehingga dapat menurunkan ambang batas nyeri 
pada ibu bersalin. Massage endhorpin pada punggung lebih mengurangi nyeri dan membuat ibu bersalin merasa lebih nyaman (Arifah,2012).

Terdapat dua macam transniter impuls nyeri berfungsi mengatur rasa sakit yaitu serabut A dan Serabut C ( reseptor berdiameter kecil ) serta transmiter yang berdiamter besar (A-Beta), ketika terjadi ransangan serabut membawa menuju medulla spinalis..Pengaruh fisiologis mempengaruhi massage endhorpin pada sirkulasi darah di bagian terdalam jaringan dan di otot, yang aman, mudah, tanpa biaya, tanpa efek samping, dan bisa dilakukan dengan bantuan orang lain. Selain itu, saat massage, tubuh mengeluarkan senyawa endorphin sebagai pereda nyeri tubuh alami dan juga membuat perasaan nyaman. Ini didukung oleh studi sebelumnya yaitu Teori nyeri menyatakan bahwa tidak menyakitkan yaitu mencegah sensasi rasa sakit dari berjalan ke sistem saraf pusat. Karena itu, stimulasi dilakukan dengan cara yang tidak berbahaya masuk mampu menekan rasa sakit. Demikian pembentukan endorfin dalam sistem kontrol. Massage bisa membuat pasien lebih nyaman karena otot relaksasi. Ini adalah salah satu non-farmakologis metode yang efektif dalam mengurangi rasa sakit. "(Tifani,2008) pembentukan endorfin dan enkefalin neuropeptida yang berperan dalam persepsi rasa sakit yang diterima oleh ujung saraf. Magnesium memiliki peran penting dalam proses fisiologis tubuh, terutama dalam penghambatan presinaps asetilkolin dan asam N-Metil-aspartat (NMDA) yang menghambat transduksi sinyal, sehingga nyeri dan kontraksi menurun. Lainnya Fungsi magnesium adalah penghambat persimpangan neuromuskuler dan inositol trifosfat yang berperan dalam pembukaan saluran kalsium dan menghambat sekresi katekolamin yang menyiratkan dalam mengurangi kekuatan uterus kontraksi dan peningkatan darah pasokan, yang mengurangi rasa sakit. hormon prostaglandin yang mempengaruhi hormon endorphin $\beta$ endorphin sebagai perantara relaksasi dan ketenangan kenyamanan (Yudianta, 2015).

Massage endhorphin juga bisa mempercepat proses involusi uterus. Efek psikologis ini menunjukkan perubahan sanogenetik sistemik. Peningkatan plasma Kadar ß-endorphin ditemukan pada akhir periode akut dari gangguan traumatis massage endorphin adalah perawatan alternatif yang menggunakan mekanisme pelepasan endorphin, mengendalikan saraf dan merangsang saraf simpatik sehingga otot menjadi relaksasi (Smeltzer, 2007).

\section{KESIMPULAN}

Berdasarkan hasil uji statistic menggunakan paired sample test atau uji $-\mathrm{t}$ sampel berpasangan dengan kemagnaan $\rho<0,05$ didapatkan hasil bahwa nilai p adalah 0,000 sehingga ada pengaruh pemberian massage endhorpin terhadap intensitas nyeri persalinan

Petugas kesehatan atau bidan harus meningkatkan mutu pelayanan kesehatan yang optimal dengan pelayanan menyeluruh dengan cara memberikan penyuluhan leaflet kepada ibu tentang massage endorphin, manfaat massage endorphin yaitu untuk mengurangi nyeri persalinan.

\section{DAFTAR PUSTAKA}

Arifah D,Mulyono B, pujiati N. 2012. Perbedaan tingkat nyeri persalinan kala I pada ibu bersalin normal primigravida dan multi gravida di Rb Nur Hikma Desa Kuwaron Gubug Grobogan tahun 2011, Jurnal Kebidanan Vol 1, No 1 (2012).Universitas muhammadiyah semarang

Antik, Lusiana, dkk.2017 . Pengaruh Endhorpin Massage Terhadap Skala Intensitas Nyeri Kala I Fase Aktif Persalianan. Jurnal Ke Jurnal Kebidanan Vol.6 No 12 April .ISSN.2089-7669 
Aryani Y, Masrul,Evareny.2015.pengaruh massage pada punggung terhadap intensitas nyeri kala I fase laten persalinan normal melalui peningkatan endorfin.jurnal kesehatan andalas 2015:4(1)

Aprillia, Y. 2010. Hipnostetri Rileks, Nyaman, dan Aman saat Hamil \& Melahirkan. Jakarta: Gagas media

Azizah, dkk. 2011. Pengaruh Endorphin Massage Terhadap Intensitas Nyeri Kala I Persalinan Normal Ibu Primipara.

Esti, H. (2012) Pengaruh masase punggung terhadap pengurangan nyeri persalinan kala I fase aktif pada ibu bersalin normal di bpm wilayah kerja puskesmas tegalrejo kabupaten magelang tahun 2012.

Judha,M.dkk. 2012. Teori Pengukuran Nyeri Persalinan,Yogyakarta: Nuha Medika

Kusuma, H .2012. Handbook FOR health Student .Yogyakarta: Medication Pusblising

Mander, 2012. Nyeri Persalinan. Jakarta : EGC

Maa W, Baib W, Lina C, Zhoua P, Xiac L, Zhaod C, Haoe Y, Maa H, Liuc X, Wangd J, Yuane H, Xieb Y, Lub A. (2011). Effects of Sanyinjiao (SP6) with electroacupuncture on labour pain in women during labour. Complementary Therapies in Medicine. 19S, S13-S18.

Mulati dkk.(2007) Perbedaan Antara Pengontrolan Nyeri Pinggang Persalinan Dengan Teknik Superficial Heat-Cold Dan Teknik Counter-Pressure Terhadap Efektivitas Pengurangan Nyeri Pinggang Pada Kala I Persalinan; Studi Di Rumah Bersalin Wilayah Klaten.Prospect,

Rahmawati,Arifah. 2013. The Influence of Back Massage toward the Decrease of Labor Pain in Active Phase Length of Stage II and Labor Bleeding in Primigravida. Kesmas National Public Healt Journal. Vol.8 no 5 desember (204-209)

Supliani E, (2017). Pengaruh Masase punggung terdapat intensitas nyeri persalinan kala I di kota bogor.Midwife Journal, Vol.3 No 01 januari (22-29)

Smeltzer \& Bare. (2007). Keperawatan Medikal Bedah. Edisi 8. Vol. 1. Jakarta: EGC Sehhatie-Shafaie F, Kazemzadeh R, Amani F \& Heshmat R. (2013). The Effect of Acupressure on Sanyinjiao and Hugo Ponts on Labor Pain in Nulliparous Women: A Randomized Clinical Trial. Journal of Caring Sciences. 2(2): 123- 129.

Tifani, Barbara dkk. 2008. Massage Therapy Reduces Pain in Pregnant Women, Alleviates Prenatal Depression In Both Parents and Improves their Relationships. Jurnal OF Bodywork and Movement Therapies.12, 146-150 
Weni, T.(2012). Perbedaan penurunan nyeri persalinan kala I antara teknik relaksasi nafas dalam denganteknik pijat effleurage yang dilakukan olehsuami pada ibu inpartu di bidan praktek swastaweni tri purnani. KTI.Program Studi Bidan Pendidik (DIV) Fakultas Ilmu Kesehatan Universitas Kadiri.

Yudiyanta, Novita Khoirunnisa, Ratih wahyu. 2015. Assesment Nyeri ( jurnal Kesehatan. CDK-226/ Vol.42 No. 3 Th 2015). Department Neurologi , Fakultas Kedokteran Universitas Gadjah mada. Yogyakarta .Indonesia 